\title{
EDITORIALS
}

\section{Measuring a Safety Culture: Critical Pathway or Academic Activity?}

\author{
Wilson D. Pace \\ Department of Family Medicine, UCHSC at Fitzsimons, PO Box 6508, Mail Stop F496, Aurora, CO 80045-0508, USA.
}

DOI: $10.1007 / \mathrm{s} 11606-006-0061-8$

(C) 2007 Society of General Internal Medicine 2007;22:155-156

$\mathrm{T}$ he Institute of Medicine (IOM) identified six core needs in a health care system, the first of which was safety. ${ }^{1}$ Furthermore, several IOM committees and others have identified the creation of a "culture of safety" as the key institutional requirement to achieve safe medical care. ${ }^{1-3}$ In this issue of the journal, Modak et al. ${ }^{4}$ present an instrument that may help measure the extent to which a patient safety culture exists in an ambulatory setting. While these authors and others have done considerable work on defining and measuring a culture of safety in the hospital setting, ${ }^{5,6}$ few have tackled the difficult task of measuring a safety culture in the ambulatory arena within the US health care system. Even in the hospital setting, where there has been more effort, the development of a culture of safety within all US hospitals has been spotty and, for some safety advocates, too slow. ${ }^{7}$

There are many potential reasons for the poor progress in developing a culture of safety: confusion about the difference between safety and quality, concerns that increasing safety will further erode profits, or perhaps simply a lack of attention by institutional leaders. Whatever the reasons for the slow pace of transformation across the nation's 5,000-plus hospitals, it is likely that this transformation will be even more difficult to achieve in the much larger and more diverse ambulatory setting. Thus, it is important to define and measure an ambulatory culture of safety.

It is also difficult, perhaps impossible, to change beliefs, attitudes, knowledge, or actions (all components of a "culture") without some form of feedback. Therefore, a necessary step in creating a culture of safety is to develop tools to measure the components of that culture. For those individuals and institutions that wish to truly improve the safety of the care they deliver, the creation and testing of tools such as the Safety Attitudes Questionnaire-Ambulatory (SAQ-A) version is critical. Beliefs, attitudes, and knowledge do not always lend themselves to clear-cut end points. Thus, we can expect to see more than one safety culture measurement

Published online January 13, 2007 instrument developed over the next several years. For instance, the Agency for Healthcare Research and Quality is also supporting the development of an instrument for use in the ambulatory setting, which is adapted from a number of hospital-oriented safety instruments. This adapted instrument should be ready for field testing early in 2007. As various ambulatory safety culture instruments are developed and evaluated, one can hope that a rich dialogue concerning the differences and similarities will ensue. Over time, the critical domains to measure, the scope and number of individuals to survey, and the interpretation of results should emerge. The Modak paper has added to and advanced this much-needed conversation.

Many clinicians and office administrators may question the need for measuring a culture of safety. They consider this to be primarily an academic enterprise-as in irrelevant. Clinicians and administrators find it hard to believe that their attitudes, knowledge, beliefs, and actions support unsafe medical care. However, evidence to the contrary continues to surface. In the recent tragedy involving the deaths of newborns in the neonatal unit of an Indiana hospital, ${ }^{8}$ the hospital administration's initial response was that this was clearly the result of human error. I was asked by several media outlets to comment on the events. To prepare for the interviews, I called a hospital pharmacy where I work to determine how similar the two vials of heparin are. The pharmacist indicated that they are similar enough that several years ago our pharmacy decided to buy these two strengths of heparin from different manufacturers so that the vials would look very different. Yes, this was a bit more work, but they believed it was an essential step needed to decrease the likelihood of an identification error. This organization demonstrated a culture of safety.

Another situation that indicates the presence or lack of a culture of safety is the handling of after-hours phone calls. Over the past several years, my colleagues and I have published a series of papers on the potential risks of policies related to the handling of after-hours phone calls by patients to primary care physicians. ${ }^{9}$ Despite attention in the medical literature $^{10}$ and the public press, ${ }^{11,12}$ our last analysis of physician offices in a number of cities across the country indicated that over $50 \%$ of offices use the same unsafe system we identified. In fact, even after we sent a number of offices in Denver, Colorado the original paper with a brief letter about how easy it was to correct the problem, 6 months later, only two had changed how they handled calls. I doubt if these 
offices believe that they are providing unsafe care or have concerns about their culture of safety. Here is where it will be informative to correlate an office's safety culture score with its decisions to act or not act when presented with information of this type. Other examples of clearly unsafe practices being accepted by clinicians, staff, and administrators abound at the hospital and ambulatory level. With the increasing complexity of medical care coupled with increasingly fragmented care, we desperately need to examine and understand our beliefs, our attitudes, our actions-our culture-concerning safety.

The SAQ-A builds on the Safety Attitudes Questionnaire for hospitals, which has been used in a number of safety-related studies. The authors' work on adapting this instrument for ambulatory use is to be applauded. Nevertheless, as they note, this report is only a first step. Over one-third of the questions from the hospital survey dropped out in the factor and reliability analyses for the modified ambulatory questionnaire. While it is likely that many of these questions are not appropriate in the ambulatory setting, it is also possible that they have not been sufficiently adapted to be of use in the ambulatory setting. Additionally, answers from nonclinical staff were all dropped in the analysis as these members of the care team did not feel they could respond to $25 \%$ or more of the questions in the survey. Clearly, these nonclinical staff members are critical parts of the care team, and their perceptions are important. Future versions of the SAQ-A should be modified to include this group.

As ambulatory safety culture tools are developed, it will be critical to measure their clinical utility. For instance, do institutions with lower indicators of a culture of safety have more errors that reach patients? Can the instrument detect changes in the culture over time? Can the instrument guide an institution's improvement process over time? Answering these questions will require a number of studies across a large number of ambulatory settings. While this work has been repeatedly identified as the first step in the journey toward a safe health care system, support for research of this nature is very difficult to secure. Modak et al. have taken the first steps. We can only hope that others will follow and that funding organizations will be able to find the means to support these important foundational efforts toward improving the safety of care in the ambulatory setting, where most of us get most of our care most of the time.

Potential Financial Conflicts of Interest: None disclosed.

Corresponding Author: Wilson D. Pace, Department of Family Medicine, UCHSC at Fitzsimons, PO Box 6508, Mail Stop F496, Aurora, CO 80045-0508, USA (e-mail: Wilson.pace@uchs.edu).

\section{REFERENCES}

1. IOM Committee on Quality of Health Care in America. Crossing the Quality Chasm: A New Health System for the 21st Century. Washington, DC: National Academy Press; 2001.

2. Institute of Medicine Committee on Identifying and Preventing Medication Errors Board on Health Care Services. Preventing Medication Errors. Washington, DC: The National Academies Press; 2006.

3. Ruchlin HS, Dubbs NL, Callahan MA. The role of leadership in instilling a culture of safety: lessons from the literature. J Healthc Manag. 2004;49(1):47-58; discussion 58-9, Jan-Feb.

4. Modak I, Sexton JB, Lux TR, Helmreich RL, Thomas EJ. Measuring safety related attitudes in the ambulatory setting: the ambulatory safety attitudes questionnaire. J Gen Intern Med. 2007; doi: 10.1007/s11606007-0114-7.

5. Sexton JB, Helmreich RL, Neilands TB, Rowan K, Vella K, Boyden J, et al. The safety attitudes questionnaire: psychometric properties, benchmarking data, and emerging research. BMC Health Serv Res. 2006;6:44.

6. Reeder JM. Patient safety: Cultural changes needed. Healthcare Papers. 2001;2(1):48-54, discussion 86-9.

7. Leape L. Lucian Leape on patient safety in U.S. hospitals. Interview by Peter I Buerhaus. J Nurs Sch. 2004;36(4):366-70.

8. Martin D. Two preemies die in Ind. after overdoses. 1918 Sep 6; Available at http://www.boston.com/news/nation/articles/2006/09/18/ human_error_blamed_for_2_preemie_deaths/. (Accessed $1911 \mathrm{Feb} 6$ ).

9. Hildebrandt DE, Westfall JM, Fernald DH, Pace WD. Harm resulting from inappropriate telephone triage in primary care. J Am Board Fam Pract. 2006; 19(5):437-42, Sep-Oct.

10. Hickner J. Patient safety after hours: Time for action. J Fam Pract. 2003;52(3):227-228, Mar.

11. O'Reilly KB. Screening after-hours calls can hurt patients. Am Med News 2006; Oct 9 .

12. Boodman SG. "Is This an Emergency?" Washington Post 2006; Oct 24. 